\title{
Evaluation of Efficacy of Transversus Abdominis Plane Block and Systemic Analgesia for Post-Operative Pain in Total Abdominal Hysterectomy: A Comparative Study
}

\author{
Menaka Viswanath ${ }^{\circledR 1}$, Ravikrishna Kalathur ${ }^{\circledR 2}$, K. Shanthini ${ }^{\circledR 3}$ \\ ${ }^{1}$ Registrar, Intensive Care Unit, Columbia Asia Hospital, India, ${ }^{2}$ Consultant, Department of Anesthesia, Apollo Hospital, ${ }^{3}$ Specialist Grade 2, Department of Anaesthesia, \\ ESIC Medical College and PGIMSR, K. K. Nagar, Chennai, Tamil Nadu, India.
}

\section{Abstract}

Introduction: Management of post-operative Pain is gaining considerable attention with pain being recognized as the fifth vital sign. Postoperative pain management remains unresolved as pain is individualized and varies with surgery. The aim is to evaluate the analgesic efficacy of transverses abdominis plane block by continuous catheter technique and systemic analgesia for post-operative pain in total abdominal hysterectomy. Subjects and Methods: This randomized controlled trial was done in patients undergoing total abdominal hysterectomy via Pfannenstiel incision. Patients were assigned into 2 groups, systemic analgesics group $(\mathrm{n}=25)$ and TAP block group ( $\mathrm{n}=25)$ randomly. Results: Out of 50 patients, 25 patients had systemic analgesics and 25 patients had TAP block. Demographics and surgical procedure times were comparable. Mean VAS pain score with coughing on day 1 and 2 in systemic analgesics group was 3.96 and 2.07 and in TAP block group were 0.7 and 0.3. Meantime taken to mobilize the patient after the surgery in the systemic analgesics group was 30.7 hours and in TAP block group was 22.4 hour. 18 patients needed rescue medication in the systemic analgesics group, and 9 patients required rescue medication in the TAP block group. In group 16 patients with systemic analgesics had post-operative nausea and vomiting, and 5 patients in group block TAP. Conclusion: Continuous TAP block provides better pain relief, denoted by lower visual analogue scores and better recovery profile enhancing recovery in patients undergoing abdominal hysterectomy.

Keywords: Post-operative Pain, Transversus abdominis plane block, Abdominal hysterectomy.

Corresponding Author: K. Shanthini, Specialist Grade 2, Department of Anaesthesia, ESIC Medical College and PGIMSR, K. K. Nagar, Chennai, Tamil Nadu, India.

E-mail: dr.shanthu@gmail.com

Received: 30 June 2020

Revised: 07 August 2020

Accepted: 13 August 2020

Published: 16 December 2020

\section{Introduction}

Effective pain relief provides a smoother post-operative course with earlier discharge from hospital, but it may also reduce the onset of chronic pain syndromes. ${ }^{[1]}$ Pain management is progressing with more selective targeting, thereby minimizing side effects, enhancing mobility, earlier discharge and avoiding late complications as in low backache and neuropathic pain. Factors influencing post-operative pain management technique are the site of surgery, familiarity with different methods of analgesia and the availability of resources to monitor in the post-operative period. ${ }^{[1]}$

Abdominal hysterectomy is a commonly performed surgery for indications like dysfunctional uterine bleeding, Fibroids and Cervical intra epithelial neoplasia. Acute blood loss compounds the cardiovascular strain posed by the coexisting chronic anaemia and the co-morbities already present. Post operative pain management with early ambulation is essential.

Systemic opoids and an epidural infusion in high risk cases have been the modalities of post operative pain management in hysterectomies. However, extensive use of opioids is associated with a variety of side effects, such as ventilatory depression, drowsiness and sedation, post-operative nausea and vomiting (PONV), pruritus, urinary retention, ileus and constipation that can delay hospital discharge. ${ }^{[2]}$ Intra- and post-operative usage of high doses of bolus or constant infusions of strong opioid analgesics can significantly enhance post-operative pain as a result of their rapid withdrawal and acute tolerance build. ${ }^{[3]}$

Blocking the afferent neural supply by local anesthetics seems to offer more advantages. Among these Transversus 
abdominis plane block and Local infiltration are preferred over epidural. Nerve blocks have, reduced incidence of hypotension, urinary retention, nausea, vomiting, backache and complications such as epidural hematoma epidural abscess and paraparesis, ${ }^{[4]}$ all of which are seen with epidural. ${ }^{[5,6]}$

While local penetration in the early post-operative cycle reduces the magnitude of incisional pain, many patients do feel severe pain as the local anesthetic effect wears off and wound infection remains a possibility. Continuous injection or occasional boluses of the surgical wound (or peripheral nerve) with local anesthetic solutions is introduced as a way to expand the incisional pain relief caused by local anesthetics into the post-operative period. ${ }^{[7,8]} \operatorname{Tr} a n$ sversus abdominis plane block is being used for post-operative pain in appendicectomy, ${ }^{[9]}$ hysterectomy, ${ }^{[10]}$ laparoscopic surgeries, ${ }^{[11]}$ retropubic prostatectomy and caesarean section. ${ }^{[12,13]}$ however, there are not many studies evaluating the analgesic effectiveness of transverse abdominal block by continuous catheter procedure and systemic analgesia.

\section{Aim}

To evaluate the efficacy of transverses abdominis plane block by continuous infusion and systemic analgesia for postoperative pain management in patients undergoing abdominal hysterectomy.

\section{Subjects and Methods}

This RCT was conducted in Apollo hospital, Chennai. Sample size was taken based on a study done by Carneyet al, ${ }^{[10]}$ and after a pilot study. Patients were assigned into 2 groups, study group who received TAP block group $(n=25)$,and control group which received the usual systemic analgesia as per the institution protocol. Randomization was done using sealed envelope technique. Inclusion criteria include ASA physical status 1 or 2 , age group between 25 to 65 years, elective total abdominal hysterectomy through Pfannenstiel incision. Exclusion criteria includes patient refusal, history of adverse reaction to local anesthetics, ASA status III, IV and $\mathrm{V}$, chronic preoperative opioid consumption, psychiatric disorders. Written informed consent was obtained from all participants.

Demographic details such as age, height, weight, surgery duration as well as clinical variables such as rest pain, dynamic pain, sedation, ambulation of patients, post-operative nausea and vomiting, systolic and diastolic blood pressure, heart rate and respiratory rate were collected. All the patients had standardized anesthetic management. They were premedicated with Tablet Alprazolam $0.5 \mathrm{mg}$ per orally the night before surgery at $10 \mathrm{pm}$. All the baseline values were recorded. Anesthesia was induced with INJ. Propofol $2 \mathrm{mg} / \mathrm{kg}$, Fentanyl $1.5 \mu \mathrm{g} / \mathrm{kg}$ and endotracheal intubation was facilitated with
Atracurium $0.5 \mathrm{mg} / \mathrm{kg}$ i.v, anesthesia was maintained with $66 \%$ nitrous oxide, $33 \%$ oxygen and Desflurane $3 \%$. All the patients were ventilated in volume control mode(Aestiva 5, Datex Ohmeda) to achieve target EtCO2 of 30-35 mmHg.

After the completion of surgical procedure in TAP group ultrasound-guided Transversus abdominis plane block was done. Residual neuromuscular blockade was reversed using Neostigmine $0.05 \mathrm{mg} / \mathrm{kg}$ and Glycopyrrolate $0.01 \mathrm{mg} / \mathrm{kg}$ in both the groups. Tracheal extubation was accomplished when the patient was hemodynamically stable, responsive and cooperative. Recovery from anesthesia was identical for all patients and the patients were shifted to the Post Anaesthesia Care Unit (PACU) for post-operative management. Patients in Group A received a bilateral Transversus abdominis block using ultrasound guidance. They were given $20 \mathrm{ml}$ of $0.25 \%$ bupivacaine as a bolus followed by $0.12 \%$ continuous infusion with $0.12 \%$ bupivacaine at $8-10 \mathrm{ml} / \mathrm{hrwas}$ infused bilaterally with infusion pumps. In systemic analgesics group, patients were given intravenous tramadol $1.5 \mathrm{mg} / \mathrm{kg} 8^{\text {th }}$ hourly and intravenous paracetamol 1 gram $8^{\text {th }}$ hourly.

In PACU, when a patient developed Pain of Visual Analogue Scale (VAS) $\geq 4$, in a 10 -point scale (where 0 , none; 10 , very severe) intramuscular Diclofenac $75 \mathrm{mg}$ was administered in both the groups. The total dosage was kept within the toxic limit. Data was tabulated and was analysed statistically

\section{Results}

Out of 50 patients, 25 patients had systemic analgesics and 25 patients had TAP block. Mean age in systemic analgesic group was 42.04 years whereas in TAP block group was 44.28 years, mean weight in TAP block group was $64.64 \mathrm{kgs}$, mean weight systemic analgesic group was $63.04 \mathrm{kgs}$, the mean height in TAP block group was $158.32 \mathrm{cms}$, the mean height in the systemic analgesic group was $159.58 \mathrm{cms}$.

The mean surgery duration in systemic analgesics group was 74 min with the shortest time being $45 \mathrm{~min}$ and the longest time being $150 \mathrm{~min}$. In the TAP block group, the mean duration was $75.2 \mathrm{~min}$ with the shortest time being $50 \mathrm{~min}$ and the longest time being 120 min. $(\mathrm{p}=0.576)$.

Patients in TAP block group reported significantly less pain at rest throughout the post-operative period. $(\mathrm{p}<0.001)$ at all-time intervals for 48 hours postoperatively.

Systemic analgesics and TAP group had a significant difference in mean pain during coughing $(\mathrm{p}<0.001)$

Out of 50 patients, 25 patients had systemic analgesics and 25 patients had TAP block. Mean VAS pain score on day 1 and 2 in systemic analgesics group was 3.96 and 2.07 and in TAP block group is 0.7 and 0.3 .rom 0 hour, in the immediate postoperative period. In 0 hour the sedation score was higher in 


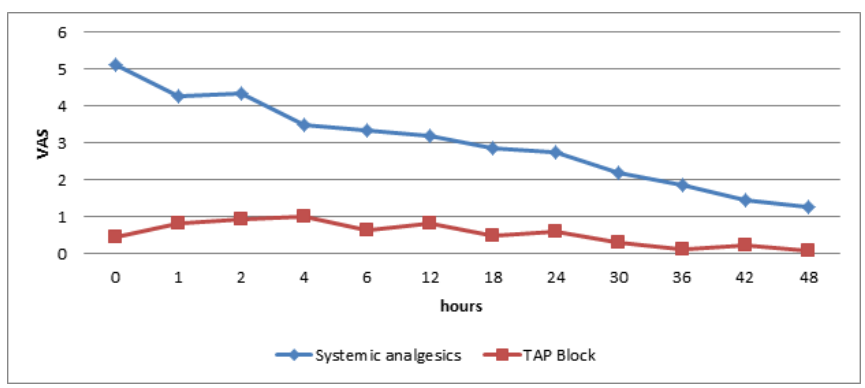

\section{Figure 1: Comparison of Pain at Rest.}

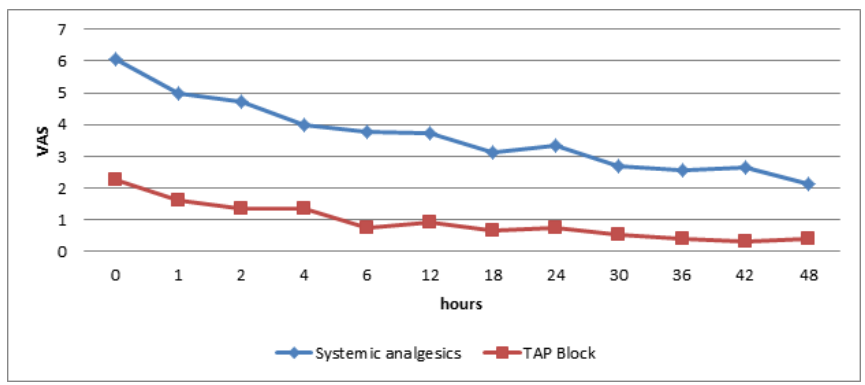

Figure 2: Comparison of pain on coughing.(Dynamic Pain)

both the groups but more in systemic analgesics group with a significant $\mathrm{p}$-value.

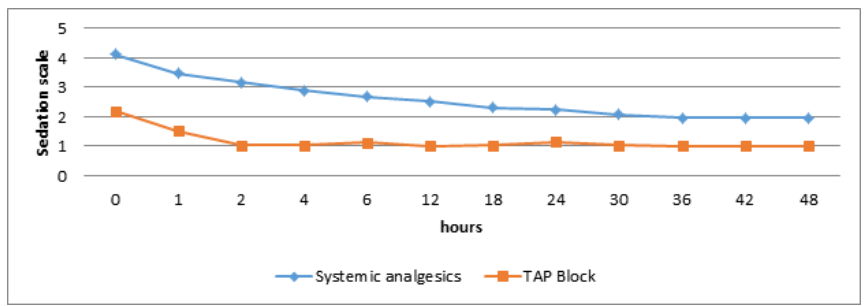

\section{Figure 3: Distribution of Sedation scale}

The mean time taken to mobilize the patient after the surgery in the TAP block group was 22.4 hours, whereas it was 30.7 hours in the systemic analgesics group. $(\mathrm{p}<0.0001)$

Rescue analgesic requirement was comparatively less in the TAP group. Out of 25 patients only 9 required rescue medication while it was 18 in systemic analgesics group. Moreover the mean of total tramadol consumption is about $800 \mathrm{mg}$ in systemic analgesics group while it was $99 \mathrm{mg}$ in TAP group that showed a significant difference $(\mathrm{p}<0.0001)$. In systemic analgesics group 16 patients had post-operative nausea and vomiting and 5 patients in TAP block group $(\mathrm{p}=0.002)$.

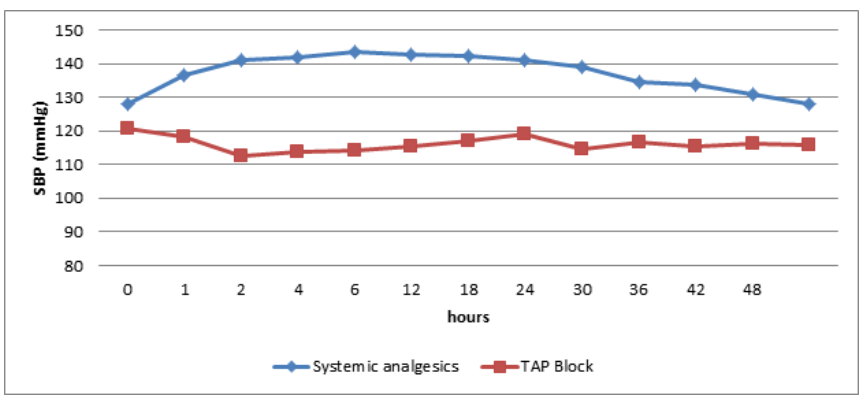

Figure 4: Comparison of Systolic blood pressures.

Both group participants were equal to each other in preoperative systolic and diastolic blood pressures.

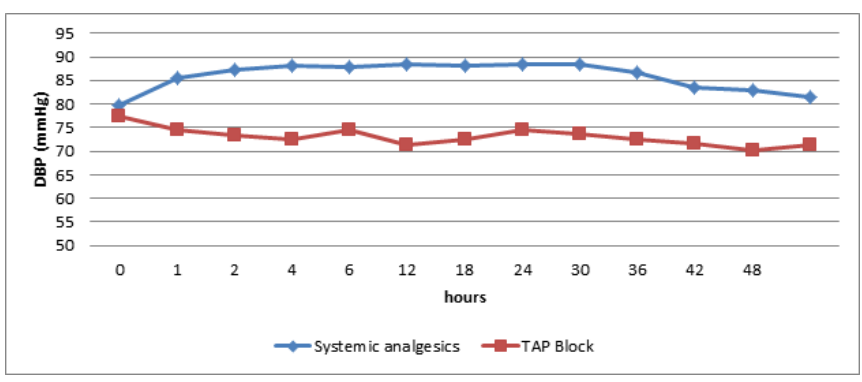

Figure 5: Comparison of Diastolic Blood Pressures.

The Heart rate was comparable in both groups during the preoperative period and the immediate post-operative period.

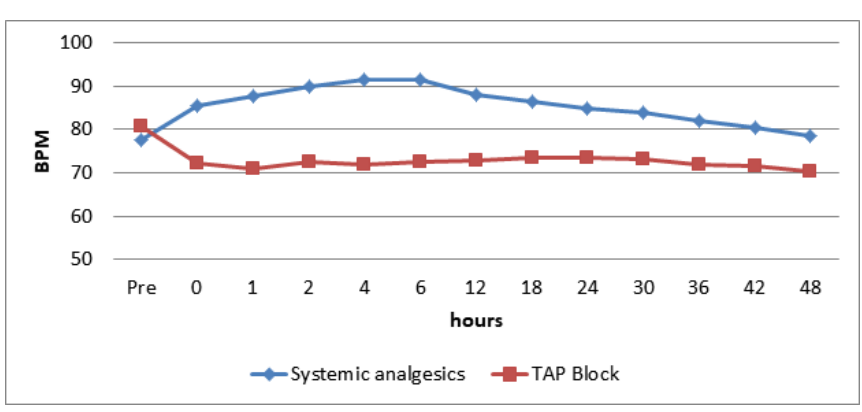

Figure 6: Comparison of Heart Rate

Respiratory rate was high in TAP group during preoperative period giving a statistically significant difference with systemic analgesics group while during the rest of the period, it is higher in systemic analgesic group. 


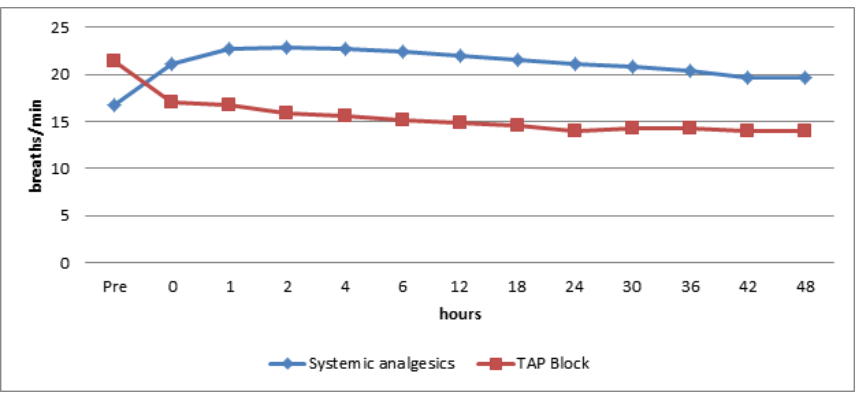

Figure 7: Comparison of Respiratory rate

\section{Discussion}

Multimodal or "balanced" analgesic techniques involving the use of smaller doses of opioid in combination with non-opioid analgesic drugs, such as local anesthetics, acetaminophen and non-steroidal anti-inflammatory drugs (NSAIDs), are becoming increasingly popular in the prevention of postoperative pain. ${ }^{[2]}$

Pain after abdominal surgeries has two components. One is the somatosensory component that arises from the surgical wound of abdominal wall and the second is the visceroperitoneal component that results from the viscera and the peritoneum. The main component of pain in elective surgeries is the one from abdominal wall incision which can be blocked by blocking the somatosensory nerves.

Transversus abdominis plane block, which blocks the nerves as it crosses the inner oblique and the transverse abdominis, was first identified as landmark based technique through the triangle of petit by Rafi in 2001. ${ }^{[14]}$ Subsequently the ultrasound-based technique was described by Hebbard has been used in providing post-operative analgesia as a part of multi modal analgesia. ${ }^{\left[{ }^{15}\right]} \mathrm{Mc}$ donnell et al showed a $47 \%$ decrease in opioid consumption after abdominal hysterectomyand Jumna et al showed a $60 \%$ reduction of morphine in caesarean delivery. ${ }^{[16,17]}$ Both the studies had incorporated TAP before the surgery and under spinal.

In our study, we had used a dose of $0.25 \%$ Bupivacaine as a bolus followed by $0.12 \%$ continuous infusion by a catheter. This would provide continuous pain relief even with movement as seen by the VAS with cough impulse. There was $50 \%$ reduction in rescue analgesic requirement, incidence of nausea, vomiting. Mobilization was earlier by $8 \mathrm{hrs}$.

So the main advantages of continuous TAP block are improved patient comfort, with decreased side effects like nausea, vomiting, sedation or respiratory depression and can be extended for 48 hrs. When compared to epidural block there is absence of sympathetic or motor deficit hence early mobilization, decreased need for catheterizations and can also be used in situations where neuraxial techniques are contraindicated. TAP blocks involves no risk to the spinal cord, and so can be used in people with spinal cord deformities. In conclusion, TAP block is a simple and effective analgesic technique, where parietal pain plays a main role in postoperative pain. Coming on to the complications of TAP block, literatures have revealed needle trauma, intraneural injection, neural ischemia, inadvertent intravascular injection, local anesthetic toxicity, infection, failed block which are common to all regional techniques. The use of ultrasound-guided TAP block is increasing because of reduced complications. The limitations are using a catheter bilaterally, which is quite cumbersome. But the VAS score throughout the study group remained less on comparison with the systemic analgesia group.

\section{Conclusion}

From this study, we conclude that analgesic efficacy of transverses abdominis plane block in Total abdominal hysterectomy is superior, and has fewer side effect profile than systemic analgesia. This plays a major role in early mobilization and recovery.

\section{References}

1. Wilson I, Eltringham R. Management of post-operative pain. Update Anaesth. 1993;2:15-21.

2. White PF. Awake and Paralyzed: Was It Really Necessary? Anesthesia \& Analgesia. 2005;101:297-297. Available from: https://dx.doi.org/10.1213/01.ane.0000156718.77197.60.

3. Guignard B, Bossard AE, Coste C, Sessler DI, Lebrault C, Alfonsi P, et al. Acute Opioid ToleranceIntraoperative Remifentanil Increases Postoperative Pain and Morphine Requirement. Anesthesiology. 2000;93(2):409-426. Available from: https://doi.org/10.1097/00000542-200008000-00019.

4. Vloka JD, Hadzic A, Mulcare R, Lesser JB, Kitain E, Thys DM. Femoral and genitofemoral nerve blocks versus spinal anesthesia for outpatients undergoing long saphenous vein stripping surgery. Anesth Analg. 1997;84(4):749-52. Available from: https://doi.org/10.1097/00000539-199704000-00009.

5. Gibbs P, Purushotham A, Auld C, Cuschieri RJ. Continuous wound perfusion with bupivacaine for postoperative wound pain. Brit J Surg. 1988;75(9):923-924. Available from: https: //dx.doi.org/10.1002/bjs.1800750934.

6. Thomas D, Lambert WG, Williams KL. The direct perfusion of surgical wounds with local anaesthetic solution: an approach to post-operative pain? Ann R Coll Surg Engl. 1983;65(4):226235.

7. LEVACK ID, HOLMES JD, ROBERTSON GS. Abdominal wound perfusion for the relief of postoperative pain. $\mathrm{Br} \mathrm{J}$ Anaesth. 1986;58(6):615-619. Available from: https://dx.doi. org/10.1093/bja/58.6.615.

8. Gupta A, Thörn SE, Axelsson K, Larsson LG, Agren G, Holmström B. Post-operative pain relief using intermittent injections 
of $0.5 \%$ ropivacaine through a catheter after laparoscopic cholecystectomy. Anesth Analg. 2002;95(2):450-456. Available from: https://doi.org/10.1097/00000539-200208000-00040.

9. Niraj G, Searle A, Mathews M, Misra V, Baban M. Analgesic efficacy of ultrasound-guided transversus abdominis plane block in patients undergoing open appendicectomy. $\mathrm{Br} \mathrm{J}$ Anaesth. 2009;103:601-606. Available from: https://doi.org/ 10.1093/bja/aep175.

10. Carney J, McDonnell JG, Ochana A, Bhinder R, Laffey JG. The Transversus Abdominis Plane Block Provides Effective Postoperative Analgesia in Patients Undergoing Total Abdominal Hysterectomy. Anesth Analg. 2008;107(6):2056-2060. Available from: https://dx.doi.org/10.1213/ane.0b013e3181871313.

11. El-Dawlatlyaa, Turkistania, Kettnersc. ultrasound guided Transversus abdominis plane block: description of a new technique and comparison with conventional systemic analgesia during laparoscopic cholecystectomy. $\mathrm{Br} \mathrm{J}$ Anaesth. 2009;102:763-770. Available from: https://doi.org/10.1093/ bja/aep067.

12. O'Donnell BD, McDonnell JG, McShane AJ. The transversus abdominis plane block in open retro pubic prostatectomy. Reg Anesth Pain Med. 2006;31(1):91. Available from: https://doi. org/10.1016/j.rapm.2005.10.006.

13. McDonnell JG, Carney GCJ, Benton A, Costello J, Maharaj $\mathrm{CH}$, Laffey JG. The Analgesic Efficacy of Transversus Abdominis Plane Block After Cesarean Delivery: A Randomized Controlled Trial. Obstet Gynecol Surv. 2008;63(5):295297. Available from: https://dx.doi.org/10.1097/01.ogx. 0000312290.42178.a0.

14. Rafi AN. Abdominal field block: a new approach via the lumbar triangle. Anaesthesia. 2001;56(10):1024-1026. Available from: https://dx.doi.org/10.1046/j.1365-2044.2001.02279-40. $\mathrm{x}$.

15. Tran TMN, Ivanusic JJ, Hebbard P, Barrington MJ. Determination of spread of injectate after ultrasound-guided transversus abdominis plane block: a cadaveric study. Br J Anaesth. 2009;102(1):123-127. Available from: https://dx.doi.org/10. 1093/bja/aen344.

16. Nitha CS, Nayak K. Effectiveness of transversus abdominis plane block using ropivacaine for postoperative analgesia in total abdominal hysterectomy patients. Ann Int Med Dent Res. 2016;2(2):94-102.

17. Baaj JM, Alsatli RA, Majaj HA, Babay ZA, Thallaj AK. Efficacy of ultrasound-guided transversus abdominis plane (TAP) block for post cesarean section delivery analgesia-a double-blind, placebo-controlled, randomized study. Middle East J Anaesthesiol. 2010;20(6):821-827.

Copyright: (C) the author(s), 2020. It is an open-access article distributed under the terms of the Creative Commons Attribution License (CC BY 4.0), which permits authors to retain ownership of the copyright for their content, and allow anyone to download, reuse, reprint, modify, distribute and/or copy the content as long as the original authors and source are cited.

How to cite this article: Viswanath $\mathrm{M}$, Kalathur R, Shanthini $\mathrm{K}$. Evaluation of Efficacy of Transversus Abdominis Plane Block and Systemic Analgesia for Post-Operative Pain in Total Abdominal Hysterectomy: A Comparative Study. Acad. Anesthesiol. Int. 2020;5(2):9-13.

DOI: dx.doi.org/10.21276/aan.2020.5.2.2

Source of Support: Nil, Conflict of Interest: None declared. 